\title{
("thing
}

\section{LÍNGUA E IDENTIDADE:A AFIRMAÇÃO DA IDENTIDADE ATRAVÉS DAS ESCOLHAS LEXICAIS EM TEXTOS JORNALÍSTICOS}

\author{
Fernando Ferreira dos SANTOS ${ }^{1}$ \\ Universidade Federal de Alfenas - UNIFAL-MG - MG \\ (fernandounifal@hotmail.com) \\ Celso FERRAREZI JÚNIOR² \\ Universidade Federal de Alfenas - UNIFAL-MG - MG \\ (cferrarezij@gmail.com)
}

\begin{abstract}
Resumo: $O$ presente artigo destina-se à análise da identidade ideológica delimitada por escolhas lexicais em discursos jornalísticos. Para recolher elementos do objeto de estudo, escolhemos pares de textos que tratam de um mesmo assunto, mas oriundos de fontes ideologicamente distintas. Pela análise das escolhas lexicais, pretendemos identificar a tentativa dos autores de construir ou reforçar sua identidade ideológica. Toma-se com referência, o conceito de identidade presente em SILVA, 2000, p. 106, a saber: a identidade é "construída a partir do reconhecimento de alguma origem comum ou de características que são partilhadas com outros grupos ou pessoas, ou ainda, a partir de um mesmo ideal".
\end{abstract}

Palavras-chaves: identidade; ideologia; escolhas lexicais; discurso.

Abstract: The present article aims to analyze the ideological identity delimited by lexical choices in journalistic discourses. In order to collect elements of the object of study, we choose pairs of texts published in different media that deal with the same subject, but come from ideologically distinct sources. By analyzing the lexical choices, we intend to identify an attempt by the authors to construct or reinforce their ideological identity. The main reference is made in the present concept in SILVA, 2000, p. 106, namely: identity is "built from the recognition of some common origin or characteristics that are shared with other groups or people, or even from the same ideal."

Keywords: identity; ideology; lexical choices; discourse.

Resumen: Este artículo pretende analizar la identidad ideológica delimitada por elecciones léxicas en los discursos periodísticos. Con el fin de recopilar elementos del objeto de estudio, seleccionamos pares de textos publicados en diferentes medios que tratan el mismo tema, pero que provienen de fuentes ideológicamente diferentes. Al analizar las elecciones léxicas, pretende identificar un intento de los autores para construir o reforzar su identidad ideológica. El concepto de identidad presente en SILVA, 2000 , p. 106, a saber: la identidad se "construye a partir del reconocimiento de algún origen común o características que se comparten con otros grupos o personas, o incluso desde el mismo ideal".

Palabras clave: identidad; ideología; elecciones léxicas; discurso.

\section{INTRODUÇÃO}

\footnotetext{
${ }^{1}$ Graduado em Letras - Licenciatura em Português pela Universidade Federal de Alfenas (2018).

2 Professor Titular da Universidade Federal de Alfenas. Doutor em Linguística - Semântica pela Universidade Federal de Rondônia (em convênio com a University of Pittsburgh) (1998), Pós-Doutor em Semântica pela Universidade Estadual de Campinas (2005) e em Linguística de Corpus pela Universidade Federal de Minas Gerais (2016).
} 
O objetivo deste artigo é identificar, em discursos jornalísticos que tratam de um mesmo assunto, mas divulgados por mídias de posições ideológicas diferentes, escolhas lexicais que busquem delimitar ideias e posições ideológicas na intenção reforçar sua identidade midiática, ao mesmo tempo em que buscam a identificação do leitor com as ideias do texto.

Vivemos em um país de regime democrático em que a expressão de ideias é livre. Quem busca suas informações em mais de um meio de comunicação, tais como revistas ou jornais, entende que uma mesma notícia pode ser dada de diferentes formas, diferenças que podem ser sutis ou não. As diferentes formas de se tratar de uma mesma notícia estão ligadas diretamente à construção e à reafirmação da identidade do autor, do veículo midiático e de seus parceiros, como mostraremos neste trabalho.

Ressaltamos que objetivo do trabalho é apenas de análise dos textos, não havendo nenhuma pretensão de analisar os porquês das escolhas ideológicas identificadas. Todo o indivíduo ou meio de imprensa tem o livre direito de expressar a sua visão dos fatos e não há nenhum questionamento quanto à parcialidade de suas ideias, ainda porque, não existe neutralidade no enunciado, como postula Foucault:

...[não há] enunciado livre, neutro e independente; mas sempre um enunciado fazendo parte de uma série ou de um conjunto, desempenhando um papel no meio dos outros, neles se apoiando e deles se distinguindo: ele se integra sempre em um jogo enunciativo, onde tem sua participação, por ligeira e ínfima que seja. [...] Não há enunciado que não suponha outros; não há nenhum que não tenha, em torno de si, um campo de coexistências. (FOUCAULT, 1986, p.114)

Assim sendo, a língua envolve todas as ações do pensamento humano, como a cultura, a ideologia e os conhecimentos e é inseparável do homem. Logo, cremos ser possível identificar, por meio da análise das escolhas lexicais de determinados textos sobre um mesmo assunto, os traços que, através de um discurso, o autor utiliza para constituir ou preservar a sua identidade.

\section{LÍNGUA E IDENTIDADE}

Antes de dar foco ao tema central deste artigo, que é a correlação da escolha do léxico com a afirmação da identidade, acreditamos ser importante apresentar, mesmo que de forma breve, conceitos de língua e identidade e suas 
relações. Hoje em dia, é aceito pela Linguística que línguas naturais são sistêmicas e seus elementos estão ligados entre si a partir de uma variedade de relações.

Inicialmente instituída no Curso de Linguística Geral atribuído a Ferdinand de Saussure, essa concepção entende a língua como um sistema de signos em que cada signo seria composto por um significante (uma imagem acústica) e um significado (uma imagem mental). O "Curso" descrevia a língua como uma herança social acabada. Porém, Noam Chomsky acredita na existência de uma Gramática Universal em todas as línguas, a qual o indivíduo, independente de sua origem, já possui ao nascer e que seria herdada geneticamente. Com base nessa gramática universal é que o ambiente em que o indivíduo cresce, tem uma função fundamental na aquisição das línguas específicas, e nessa interação da gramática internalizada com o ambiente social, se desenvolve a gramática dos falantes de cada língua.

Mas sabemos que a língua, mais do que um instrumento neutro de comunicação, herdada ou não, é também uma das formas existentes de registro do enorme trabalho coletivo feito para descrever os mundos que concebemos culturalmente. Assim, cada língua carrega em si as singularidades e as identidades de seus falantes.

Dessa forma, como a sociedade vive em constantes mudanças, a língua não é diferente, pois sofre mudanças decorrentes de fatores sociais, políticos e do próprio tempo. Ela é muito mais complexa do que postula a teoria do sistema de signos, que é muito mais focada em questões estruturais das línguas, dando mais valor às estruturas sistêmicas que aos sentidos, à funcionalidade e à finalidade comunicativa.

Com o objetivo de se realizar um estudo mais amplo das línguas naturais, levando em conta o ambiente sociocultural e a identidade, surgiram os estudos sociolinguísticos. Assim, a Sociolinguística se torna a parte da Linguística que estuda as conexões entre linguagem e sociedade e a forma como utilizamos a linguagem em diversas situações sociais.

Esses avanços científicos permitiram que até os conceitos de língua mudassem. A língua não é mais tida como engessada, mas, sim, como um sistema mutável e variável que se constrói ao longo da história. Segundo MARCUSCHI (2000), "a língua é uma atividade de natureza sócio cognitiva, histórica e situacionalmente desenvolvida para promover a interação humana". Por isso, é impossível estudar a língua, sem levar em conta o falante e a cultura na qual este está inserido. Passa-se 
a dar importância à funcionalidade da língua assim como sua intencionalidade, já que a linguagem é a base ou o suporte pelo qual tudo passa de um indivíduo para outro.

[...] com efeito, a compreensão do fenômeno linguístico como atividade, como um dos fazeres do homem, puxou os estudos da língua para a consideração das intenções sociocomunicativas que põem os interlocutores em interação; acendeu, além disso, o interesse pelos efeitos de sentido que os interlocutores pretendem conseguir com as palavras em suas atividades de interlocução. (ANTUNES, 2009.p.20)

Sendo assim, através da comunicação entre os indivíduos, a língua se torna viva. Ela se molda aos desejos e intenções dos falantes, de acordo com o objetivo ao utilizá-la. A língua e o sujeito são inseparáveis e ela não se resume mais a conjuntos binários de significante e significado, mas é, agora, vista como um fenômeno social bem mais complexo. A língua é constituída pelo sujeito e o sujeito, em grande parte, pela língua. Através dela, ele constrói grande parte de sua identidade e a transmite. Carregada de sua ideologia, na maioria das vezes, esta interação serve para determinar uma relação de poder entre os falantes. A língua imprime, assim, traços de identidade e legitimidade.

Uma vez que somos, em grande parte, constituídos pela língua, construímos nossa identidade através da interação com o mundo, interação esta, que nos modifica e, consequentemente, modifica o mundo. Para entender um pouco melhor esta identidade, que é modificada, ao mesmo tempo que se torna um agente modificador através da língua, tomaremos como eixo as ideias de HALL (2000). O autor nos apresenta três concepções de identidade:

A primeira se refere ao sujeito como concebido pelo lluminismo, que era dotado de consciência e que possuía um núcleo interior que era construído no nascimento e não se modificava no decorrer do seu desenvolvimento. Este sujeito era o centro de tudo e a presença de outros sujeitos não modificava esse "eu".

A segunda concepção de identidade apresentada por Hall é do sujeito sociológico, que segundo o autor, refletia a crescente complexidade do mundo moderno, este sujeito que não era independente e autossuficiente, mas construído na relação com outras pessoas importantes para ele, realizando esta transição de valores, sentidos e símbolos. Nesta visão de sujeito, em que se evidencia a importância do caráter social da linguagem, temos a preocupação do modo como nos expressamos, uma vez que este altera como somos reconhecidos pelas pessoas de 
nosso grupo. Existe, aí, a necessidade de uma autoafirmação da identidade, esta que é coletivamente construída.

Já o indivíduo contemporâneo, na visão de Hall, não apresenta apenas uma identidade, mas várias delas. Identidades, que, segundo Hall, se modificam constantemente. Nessa nova visão, a identidade do homem pós-moderno é fragmentada em várias identidades que são instáveis e construídas historicamente. Ainda, segundo o autor, é ilusão imaginar que temos uma identidade fixa. HALL (2000, p.16) destaca: "se sentirmos que temos uma identidade unificada desde o nascimento até a morte, é apenas porque construímos uma cômoda estória sobre nós mesmos ou uma confortadora narrativa do eu".

O homem pós-moderno questiona valores que até então eram tidos como sólidos. As identidades ideológicas, tais como de gênero, política, religiosa, linguística e outras, sofrem mudanças que são impulsionadas pela globalização. É neste contexto que pretendemos realizar nossa análise. (HALL, 2005, p. 13) afirma que "o sujeito assume diferentes identidades em diferentes momentos, identidades que não são unificadas ao redor de um 'eu' coerente". Apesar de, muitas vezes, termos uma visão polarizada da identidade política, seja ela polarizada entre direita ou esquerda, liberalista ou conservadora, as identidades possuem um caráter menos simplista, sendo, cada indivíduo dividido em diversos fragmentos ideológicos.

\section{IDENTIDADE E LÉXICO}

Ao longo do tempo, o termo ideologia foi utilizado sob uma concepção crítica, como se refletisse um instrumento de dominação que age por meio de convencimento, persuasão, e não por força física, alienando a consciência humana. A Sociologia descreve a ideologia como uma associação de representações e ideias que um determinado grupo social produz a respeito do seu meio envolvente e da sua função nesse meio. Logo, o que o indivíduo pensa e no que acredita está vinculado ao seu meio social.

Um grupo defensor de uma determinada identidade ideológica frequentemente tenta convencer outras pessoas a seguirem essa mesma corrente. Assim, existem confrontos ideológicos e consequentemente ideologias dominantes (hegemônicas ou unívocas) e dominadas (subordinadas ou equívocas). Como 
veremos a seguir, os indivíduos buscam, primordialmente através do discurso, atuar sobre esse "status" ideológico para a sua manutenção ou a sua mudança.

Os discursos possuem determinados aspectos sociais dependendo do grupo em que estão inseridos. Esses grupos, sejam políticos, religiosos, regionais, profissionais, etc., possuem uma ideologia própria e utilizam da linguagem como uma das ferramentas para divulgá-la, podendo, assim, captar novos membros para reforçar tal identidade ideológica. Esse modelo de discurso une, identifica os indivíduos e dá uma sensação de poder e força entre eles.

A língua se molda a serviço do sujeito no intuito de reafirmar a sua identidade, defendendo a sua participação dentro de determinado grupo social. A identificação não é, somente, a afirmação daquilo que cada um é, mas a afirmação daquilo que não se é. E todo esse jogo de identificação dos sujeitos através das escolhas linguísticas tem uma estreita relação com a busca dos grupos pelo poder, como afirma Silva:

A afirmação da identidade e a enunciação da diferença traduzem o desejo dos diferentes grupos sociais, assimetricamente situados, de garantir $\mathrm{o}$ acesso privilegiado aos bens sociais. A identidade e a diferença estão, pois, em estreita conexão com relações de poder. $O$ poder de definir a identidade e de marcar a diferença não pode ser separado das relações mais amplas de poder. A identidade e a diferença não são, nunca, inocentes. (SILVA, 2000, p.81)

O sujeito, ao construir o discurso, buscando a diferenciação dos demais grupos, molda seu conteúdo e sua forma a fim de legitimar uma ideia. Um artifício utilizado na busca dessa diferenciação é a escolha lexical, ou seja, a seleção das palavras que o sujeito irá usar para denominar determinados elementos do mundo contemplados em seu discurso, assim como aqueles que serão destacados ou esquecidos no texto. Essas escolhas reforçam ou enfraquecem determinadas informações, posturas ideológicas ou focos discursivos, de acordo com a necessidade de reforçar uma opinião. Ao analisar dois discursos antagônicos, podemos verificar, nas escolhas lexicais próprias de cada um, que cada sujeito, tendo a sua opinião formada em determinado assunto, através da escolha dos termos, reforça a sua "identidade discursiva", e molda seu discurso com a finalidade de construir e preservar essa identidade.

Segundo Maingueneau (2005, p. 103), "cada discurso repousa, de fato, sobre um conjunto de semas repartidos em dois registros: de um lado os semas 
'positivos', reivindicados; de outro, os semas 'negativos', rejeitados." Ou seja, cada discurso ideológico possui um agrupamento lexical típico e, dentro dele, teremos os semas positivos, provenientes do meu discurso, da minha posição ideológica e os semas negativos, ou seja, a interpretação que eu faço dos enunciados do discurso da outra posição ideológica. Através do meu discurso, eu construo e reafirmo a minha identidade, ao mesmo tempo em que traduzo e simulo os enunciados do discurso opostamente situado, com o objetivo de enfraquecê-lo e deslegitimá-lo.

\section{PESQUISA}

\section{1 $O$ conceito de identidade}

Buscando analisar como o sujeito trabalha a escolha lexical para defender uma identidade ideológica, selecionamos quatro textos de órgãos de imprensa de tendências políticas distintas.

Vale lembrar que, apesar de o sujeito buscar sempre construir e preservar sua identidade, essa não se constitui em um objeto imutável. O sujeito pós-moderno passa hoje por um processo de constantes mudanças nas quais o livre acesso à informação e à opinião contribuiu para uma sociedade constituída de ideias e valores fragmentados e variáveis. As velhas identidades estabilizadas e com valores sólidos estão em declínio, tomando o seu lugar, estão as novas identidades, constituindo-se em um sujeito de identidades multifacetadas.

Essa identidade múltipla, fragmentada e adquirida através das experiências sociais, não é permanente. Segundo HALL (2004, p. 12): "O próprio processo de identificação, através do qual nos projetamos em nossas identidades culturais, tornouse mais provisório, variável e problemático". Toda essa instabilidade justifica os esforços dos enunciados na tentativa de convencer esse indivíduo pós-moderno.

Levando em conta toda essa fragmentação e contraditoriedade da identidade, não faz sentido, na maioria dos casos, a simplista classificação ideológica dicotômica do indivíduo entre direita e esquerda. As identidades do sujeito pósmoderno estão se fragmentando, fazendo surgir várias identidades contraditórias e não resolvidas. $O$ indivíduo assume diferentes identidades em diferentes momentos, e este, nos diversos debates a que é exposto, participa de diferentes divisões, assumindo uma grande variedade de posições, nem sempre partilhando da mesma 
opinião com as mesmas pessoas. SILVA (2000, p.97) também defende essa instabilidade da identidade, dizendo que ela "é um significado - cultural e socialmente atribuído... [não é] fixa, estável, coerente, unificada, permanente [...] tampouco é homogênea, definitiva, acabada, idêntica...”. A identidade do sujeito pós-moderno está em constante construção, é instável, contraditória, fragmentada, inconsistente e inacabada.

\subsection{A ideologia no léxico: a análise dos textos}

$\mathrm{Na}$ escolha nos textos para análise, optamos por temas bastante polarizados politicamente, tais como aborto e o governo militar de 64 . Como pudemos ver até aqui, a nossa sociedade possui identidades multifacetadas e, apesar de alguns movimentos tenderem a possuir várias identidades ideológicas em comum, as identidades não são fixas, tendendo a se modificar historicamente.

O primeiro tema que iremos analisar é o resultado final dos trabalhos da Comissão Nacional da Verdade (CNV), que foi criada com o objetivo de investigar as violações dos direitos humanos durante o período militar no Brasil. Para isso, utilizamos um texto do site da Revista Veja, datado de 10/12/2014 e intitulado de "Comissão da Verdade ressuscita debate por flexibilização da Lei de Anistia", de Gabriel Castro, e outro, do site da Revista Carta Capital, datado também de 10/12/2014, intitulado de "Comissão da Verdade pede a revisão da Lei da Anistia. Revista Carta Capital" de José Antônio Lima. As duas revistas são, reconhecidamente, pertencentes a posições ideológicas distintas.

Nos textos sobre a CNV, os próprios títulos trazem escolhas lexicais reveladoras que se referem a uma mesma situação: a reivindicação por mudanças na Lei da Anistia, de 28/08/1979. Para isso, o artigo da Revista Veja, utiliza a palavra "flexibilização", que remete à ideia de uma dobra nas regras, na dobra de algo que já está estável, enquanto a Carta Capital utiliza o termo "revisão", que remete a uma análise para a identificação e uma possível reparação de determinados erros. Os títulos, portanto, já nos dão a ideia da posição ideológica dos autores na interpretação destes fatos históricos.

A Lei da Anistia também ganha um tratamento diferente nos dois textos. $O$ autor do artigo da Revista Veja utiliza palavras em seu texto na tentativa de levar o leitor a enxergar a anistia como um elemento que beneficiou os dois lados, 
principalmente quando diz que "a corte manteve a anistia completa a representantes dos dois lados envolvidos", enquanto o autor do artigo da Carta Capital utiliza uma variação do termo, incluindo o prefixo "auto", quando se refere à Lei como uma "auto anistia promovida pelo regime ditatorial brasileiro", modificando completamente o sentido outrora utilizado, pois enquanto "anistia" significaria um perdão generalizado, "auto anistia" significa uma perdão que alguém concede a si mesmo.

O regime militar, evento ainda recente na história do Brasil, divide a ideia da população até os dias de hoje. Uma parte se identifica ideologicamente com aqueles que defendem o regime militar enquanto outra parte se identifica com aqueles que lutaram contra o regime, e cada uma destas partes, no intuito de "constituir e preservar essa identidade" (MAINGUENEAU, 2005, p.103), molda seu discurso utilizando escolhas lexicais que evidenciam essa divisão. Gabriel Castro, em certo momento do texto, quando se refere aos movimentos de esquerda na época do regime, os descreve como "aqueles que, com ou sem armas, lutaram contra o regime militar". Primeiramente, vemos que o jornalista utiliza propositalmente da palavra "armas", que vai dialogar diretamente com o texto de opinião oposta, na tentativa de descontruir a ideia de vitimismo em relação ao evento ocorrido. No entanto, chamo atenção para a escolha do termo "aqueles", que de acordo com o dicionário Aulete, "indica ou refere-se à pessoa ou coisa distante do ouvinte e do falante, no tempo ou no espaço", se referindo a esses sujeitos como distantes do autor: são, enfim, "os outros". Como a intenção do autor é buscar uma identificação do leitor com as ideias do texto, este busca sempre criar uma dicotomia, "nós-eles", trazendo o leitor para mais perto de seu campo de ideias. Por outro lado, José Antônio Lima busca uma identificação do leitor com os críticos do regime quando ele menciona as violações dos direitos humanos na seguinte sentença: "a investigação de graves violações de direitos humanos". Notamos que o escritor utiliza o adjetivo "graves", intensificando subjetivamente as "violações" do regime militar, praticamente passados em branco pelo primeiro texto. Além disso, o uso geral do termo "direitos humanos" nesta sentença (ao invés, por exemplo, de "direitos das pessoas perseguidas pelo regime") faz com que o leitor se identifique com aqueles que foram perseguidos e presos pelos militares à época.

Concluindo a análise deste texto, veremos como as duas publicações se referem àqueles acometidos pela violência do regime militar. O jornalista da Veja, menciona tais personagens na seguinte sentença: "o relatório apresentado nesta 
quarta omite crimes cometidos por grupos radicais de esquerda", ou seja, foca nos crimes cometidos pelo movimento de esquerda ao mesmo tempo que utiliza o termo "radicais", no sentido de intransigentes e inflexíveis. Por outro lado, o jornalista da Carta os descreve na seguinte sentença: "impedindo às vítimas e a seus familiares o acesso à justiça", sendo que "vítima" de acordo com o dicionário Aulete, tem o sentido de "pessoa que sofre um acidente ou desgraça gerados por causas humanas; aquele que está sendo afetado sem a possibilidade de defender-se", focando assim, nos crimes cometidos pelos agentes do regime. Se a seguinte sentença também descreve as vítimas como aqueles que são impedidos de buscar justiça pelos fatos expostos, o jornalista da Veja, na frase: "Mas os insatisfeitos com a decisão pretendem usar outro fato para retomar o pedido ao STF" se refere a estes como "insatisfeitos" agregando um sentido atenuante, que despreza a condição dos prisioneiros do regime em uma tentativa de enfraquecer o discurso alheio.

Portanto, verificamos nesses textos, como os autores moldam seu discurso através das escolhas lexicais, alterando profundamente 0 foco da exposição jornalística dos fatos. Com isso, cada texto se torna uma projeção de identidade ideológica ao mesmo tempo em que busca trazer os leitores a se identificar com ele, seja com o intuito de manutenção do status ideológico ou a aquisição deste.

O outro texto, que escolhemos para a análise, se refere ao Estatuto do Nascituro. Um projeto de lei de 2007 que ainda está em discussão no Congresso e que tem sido alvo de muitas críticas por se tratar de um tema muito polêmico, que é o debate do direito à vida desde a concepção em contraposição ao direito de escolha da mulher de permitir o nascimento do feto. A polêmica desse projeto de lei está no fato de ele envolver questões de ordem ética e moral muito fortes e "pontos de honra" para muitos grupos religiosos presentes no Brasil. Para a análise, escolhemos dois textos, sendo um, o "Estatuto do Nascituro - em defesa da vida", publicado pela CNBB - Conferência Nacional dos Bispos do Brasil, em 18/06/2013, e o outro, o “Bolsa Estupro': quando a vítima se torna criminosa", publicado em 06/06/2013 pela Revista Carta Capital. Este é mais um assunto que divide opiniões identitárias no campo ideológico. Em um texto, temos aqueles que defendem a liberdade de escolha da mulher de interromper ou não uma gravidez, entendendo que a vida não começa a partir da sua concepção, representados pela colunista Marsílea Gombata da Carta Capital e, em outro, temos os que defendem que a vida começa a partir da sua 
concepção, aqui representados pelo Cardeal Odilo Pedro Scherer, autor do texto da CNBB.

Como o que importa nesta análise é a escolha do léxico, devemos iniciar a análise já levando em conta a escolha dos títulos em si. Fica claro que os textos focam em sujeitos diferentes e de forma muito incisiva. O texto da Carta Capital menciona a mulher, considerada como vítima de estupro e transformada em criminosa se desejar interromper a gravidez. O outro menciona a defesa da vida, neste caso, se referindo ao feto desde o período da concepção até seu nascimento. Os títulos apregoam o conteúdo dos textos e são exatamente esses dois indivíduos ("mulher" e "feto") que abordaremos agora, analisando a forma como eles são descritos nos textos.

Começando pela figura da progenitora, podemos notar que ela é referida de maneiras diferentes em cada um dos textos. No texto da Carta Capital, a palavra mais utilizada para se referir à mulher é "vítima", em um total de sete vezes; o segundo termo utilizado é "mulher" (seis vezes); na sequência, é utilizado o termo "criminosa", utilizado três vezes apenas em uma alusão ao discurso contra o aborto, e por último, o termo "mãe", utilizado duas vezes, mas somente quando se refere ao texto da lei ou ao quando se refere à mulher no momento em que o bebê já tenha nascido. Este é um caso claro da repartição de semas, abordado por Maingueneau, como exposto em citação anterior, em que temos uma escolha das palavras "mulher" e "vítima", como semas positivos, defendidos pelo autor, e dos semas "criminosa" e "mãe", em uma referência ao discurso do outro, do anti-aborto, o qual é rejeitado e em relação ao qual há uma tentativa de desqualificação.

Já no texto da CNBB, apesar de mais longo, os termos para se referir à progenitora são encontrados apenas nove vezes, mostrando que a figura dela é não é o foco do discurso e aparece sempre de forma muito mais neutra em comparação ao texto da Carta. As escolhas para representar a figura desta personagem no texto, são: "mãe" e "mulher", e ainda que o termo "mulher" seja o mais utilizado no discurso, em uma total de cinco vezes, ele quase sempre se refere ao discurso alheio, como nos exemplos:

"Certo discurso em favor da legalização do aborto pretende que unicamente a mulher tenha o direito a decidir sobre o fruto de suas entranhas [...] o argumento é que o direito do nascituro diminuiria o direito da mulher [...] É falacioso argumentar que uma lei favorável aos direitos do nascituro seria prejudicial para os direitos da mulher ..." (grifos nossos) 
Notem que não apenas a escolha do léxico molda a discurso do indivíduo, mas também a escolha de utilizar ou não a menção de certos acontecimentos ou personagens, deixando-os em primeiro ou segundo plano dentro do discurso. Como já foi dito acima, no artigo da CNBB, a figura da progenitora aparece apenas nove vezes, enquanto a figura do feto aparece num total de trinta vezes. Doze vezes utilizando a palavra "nascituro", nove vezes utilizando a palavra "ser humano", cinco vezes, a palavra "filho", uma vez, a palavra "bebê" e uma vez, a palavra "coisa", essa última, sendo mais um exemplo da divisão do sema negativo, referindo-se ao discurso do outro, buscando sempre desqualificá-lo, com o objetivo de dificultar uma identificação com o outro. Portanto, num jogo de focos e ocultações, os dois autores criam pontos de atenção em seus textos, ora defendendo o direito de uma mulher "vitimizada por uma gravidez", ora defendendo o direito à vida de um feto "vitimizado por um possível aborto". Em ambos os casos, os argumentos sempre buscam identificação com valores éticos e morais, com direitos inalienáveis e, sem dúvida, com sentimentos humanos.

\section{CONCLUSÃO}

Como vimos, a língua e o sujeito são duas coisas inseparáveis. Também sabemos que não se pode pensar na ideia de um sujeito único, nem mesmo uma dicotomia simplista de dois movimentos ideológicos com apenas duas identidades, pois temos um indivíduo descentrado, fragmentado, deslocado e composto por várias identidades.

Assim, neste trabalho, embora tenhamos tocado em apenas dois assuntos e analisado apenas quatro textos, pudemos demonstrar como os discursos dos veículos midiáticos se moldam a uma identidade ideológica, não apenas para reforçar a sua ideia, mas na tentativa de conquistar a identificação do interlocutor, identidades estas, que estão em constante formação.

Como asseverou Bakhtin, "a palavra penetra literalmente em todas as relações entre indivíduos, nas relações de colaboração, nas de base ideológica, nos encontros fortuitos da vida cotidiana, nas relações de caráter político etc" (BAKHTIN, 1997 , p. 41). As palavras estão presentes em todas as relações sociais, modelando debates ideológicos e ressaltando a fragmentada identidade do homem contemporâneo. Poderíamos analisar aqui muitos outros assuntos e textos e, sem 
dúvida, encontraríamos em seus discursos determinadas estratégias que provariam cada vez mais a tese de que língua, ideologia e identidade são elementos inseparáveis e marcados nos textos por meio de recursos estruturantes identificáveis, entre eles, os recursos da escolha e da ocultação lexicais.

\section{REFERÊNCIAS}

BAKHTIN, Mikhail. Marxismo e Filosofia da Linguagem. 9. ed. São Paulo: HUCITEC, 1999.

ANTUNES, Irandé. Língua, texto e ensino: outra escola possível. São Paulo: Parábola Editorial, 2009.

CASTRO, Gabriel. Comissão da Verdade ressuscita debate por flexibilização da Lei de Anistia. Revista VEJA, 10 dez. 2014. Disponível em: $<$ https://veja.abril.com.br/brasil/comissao-da-verdade-ressuscita-debate-porflexibilizacao-da-lei-de-anistia/>. Acesso em 01 ago. 2018

CHOMSKY, N. Reflexões sobre a linguagem. São Paulo: Martins Fontes, 1975

FOUCAULT. M. A Arqueologia do saber. 5. ed. Rio de Janeiro: Forense Universitária, 1997.

HALL, S. A identidade cultural na pós-modernidade. 11. ed. Rio de Janeiro: DP\&A, 2006.

GOMBATA, Marsílea. 'Bolsa Estupro': quando a vítima se torna criminosa. Revista Carta Capital, 06 jun. 2013, Disponível em: <https://www.cartacapital.com.br/politica/2018bolsa-estupro2019-e-risco-detransformar-vitima-em-criminosa-1925.html>. Acessado em: 01 ago. 2018

HALL, S. Quem precisa de identidade? In: da Silva, Tomas Tadeu. (org.) Identidade e Diferença: a perspectiva dos estudos culturais. Petrópolis: Vozes, 2000. p. 103133.

HJELMSLEV, L. Prolegômenos a uma teoria da linguagem. São Paulo: Perspectiva, 1975.

LIMA, José Antonio. Comissão da Verdade pede a revisão da Lei da Anistia. Revista Carta Capital, 10 dez. 2014. Disponível em: <https://www.cartacapital.com.br/sociedade/comissao-da-verdade-pede-a-revisaoda-lei-da-anistia-3171.html>. Acesso em 01 ago. 2018

MAINGUENEAU, Dominique. Gênese dos Discursos. Curitiba: Criar Edições (2005). 
MARCUSCHI, Luiz Antônio. O papel da lingüística no ensino de língua. Conferência pronunciada no $1^{\circ}$ Encontro de estudos Linguísticos-Culturais da UFPE, Recife, 2000.

SAUSSURE, Ferdinand de. Curso de Linguística geral. Organização de Charles Bally e Albert Sechehaye com a colaboração de Albert Riedlinger. Trad. de Antônio Chelini, José Paulo Paes e Izidoro Blikstein. 24르 ed. São Paulo: Pensamento-Cultrix, 2002.

SCHERER, Cardeal Odilo Pedro. Estatuto do Nascituro - em defesa da vida. Arquidiocese do Rio de Janeiro, 02 dez. 2013, Disponível em: <http://arqrio.org/formacao/detalhes/207/estatuto-do-nascituro-em-defesa-da-vida>. Acesso em 01 ago. 2018

SILVA, Tomaz Tadeu. A produção social da identidade e da diferença. SILVA, Tomaz Tadeu (org.). In: Identidade e diferença. A perspectiva dos Estudos culturais. Petrópolis: Vozes, 2.000, pág. 73-102 


\section{ADENDO A}

Veja, 10/12/2014 - Comissão da Verdade ressuscita debate por flexibilização da Lei de Anistia Nova tentativa de punição a agentes da ditadura tenta ressuscitar discussão já encerrada pelo Supremo. Dilma não deu sinais de que encampará o esforço

Por Gabriel Castro, de Brasília, 10 dez 2014, 17h23

O fim dos trabalhos da Comissão Nacional da Verdade (CNV) não significa o encerramento do debate sobre a punição a agentes que cometeram crimes durante a ditadura. Pelo contrário: com o relatório final concluído, deve aumentar a pressão para que a interpretação da Lei da Anistia seja revista, de modo a permitir a punição a figuras ligadas ao regime militar.

A CNV começou a funcionar em 2012 com o objetivo declarado de investigar violações dos direitos humanos durante o regime militar e, ao mesmo tempo, promover a reconciliação nacional. No momento em que a comissão encerra seus trabalhos, entretanto, o segundo objetivo parece ter sido deixado em segundo plano. Do início ao fim, o relatório apresentado nesta quarta omite crimes cometidos por grupos radicais de esquerda e trata como meras organizações políticas alguns grupos que, na verdade, eram organizações armadas que defendiam um regime tão ou mais autoritário quanto o que estava no poder.

O apelo em favor da punição a agentes públicos da época, a despeito da Lei da Anistia, tampouco colabora com a pacificação dos ânimos. A sugestão é feita pelo próprio relatório da CNV, sob o argumento de que crimes contra a humanidade são imprescritíveis. O ex-ministro da Justiça José Carlos Dias, que integrou o grupo, afirmou nesta quarta-feira que é preciso reinterpretar a lei: "Não me parece que nós temos que fazer revisão da Lei da Anistia, mas proclamar que a anistia não se estende aos agentes do Estado que praticaram excessos e violência contra os que se apuseram", disse ele. Já há quem esteja disposto a patrocinar a causa: o presidente da Ordem dos Advogados do Brasil $(\mathrm{OAB})$, Marcus Vinícius Furtado, prometeu nesta quarta-feira empenho para "perseguir a responsabilização dos agentes do Estado que perpetraram crimes de lesa-humanidade". Ex-ministro da Secretaria de Direitos Humanos, Paulo Vannuchi endossou a tese.

A nova tentativa de punição a agentes da ditadura tenta ressuscitar uma discussão já encerrada pelo Supremo Tribunal Federal. Em abril de 2010, por 7 votos a 2, a corte manteve a anistia completa a representantes dos dois lados envolvidos no conflito da época. Mas os insatisfeitos com a decisão pretendem usar outro fato para retomar o pedido ao STF: em dezembro do mesmo ano, a Corte Interamericana de Direitos Humanos condenou o Brasil por não ter punido os responsáveis por abusos durante a ditadura.

A composição do STF se alterou significativamente desde então. Dos ministros que votaram na época, quatro permanecem na corte. Gilmar Mendes, Marco Aurélio Mello e Cármen Lúcia se opuseram à punição aos militares, enquanto Ricardo Lewandowski, atual presidente, defendeu a flexibilização da Lei da Anistia. A nova composição da corte, entretanto, não permite uma previsão clara sobre o resultado de um novo julgamento sobre o tema.

Ao mesmo tempo em que exalta aqueles que, com ou sem armas, lutaram contra o regime militar, o governo não parece disposto a encampar o esforço pela punição retroativa. É o que a presidente Dilma Rousseff deu a entender no discurso que fez após receber o relatório da CNV, nesta quarta. "Nós jamais poderemos deixar de enaltecer esses lutadores e lutadoras, mas também reconhecemos e valorizamos os pactos políticos que nos levaram à redemocratização", disse ela.

\section{ADENDO B}

\section{Carta Capital, 10/12/2014 - Comissão da Verdade pede a revisão da Lei da Anistia}

Em seu relatório final, a CNV afirma que a autoanistia promovida pelo regime ditatorial brasileiro é ilegal diante da legislação internacional

por José Antonio Lima — publicado 10/12/2014 10h51 Após mais de dois anos de trabalho a respeito das violações de direitos humanos cometidas durante a ditadura (1964-1985), a Comissão Nacional da Verdade decidiu pedir, em relatório final tornado público nesta quarta - feira 10, a revisão da Lei da Anistia, que há 35 anos mantém impunes os crimes de lesahumanidade daquele período. Para a CNV, a lei 6.683, de 28 de agosto de 1979, é uma lei de autoanistia, o que viola leis internacionais.

A anistia, segundo a CNV, não poderia incluir agentes públicos que realizaram crimes como "detenções ilegais e arbitrárias, tortura, execuções, desaparecimentos forçados e ocultação de cadáveres", pois tais ilícitos são "incompatíveis com o direito brasileiro e a ordem jurídica internacional", uma vez que se tratam de crimes contra a humanidade, "imprescritíveis e não passíveis de anistia". A CNV afirma que a jurisprudência internacional endossa "a total impossibilidade de lei interna", como é a da anistia, "afastar a obrigação jurídica do Estado de investigar, processar, punir e reparar tais crimes". 
Em sua argumentação, a Comissão da Verdade invoca a decisão da Corte Interamericana de Direitos Humanos, que em 2010 responsabilizou o Brasil pelo desaparecimento de participantes da Guerrilha do Araguaia e considerou que as disposições da lei da anistia "são manifestamente incompatíveis com a Convenção Americana sobre Direitos Humanos, carecem de efeitos jurídicos e não podem seguir representando um obstáculo para a investigação de graves violações de direitos humanos, nem para a identificação e punição dos responsáveis."

Por fim, afirma a CNV, leis de autoanistia "constituem ilícito internacional", pois "perpetuam a impunidade" e "propiciam uma injustiça continuada, impedindo às vítimas e a seus familiares o acesso à justiça, em direta afronta ao dever do Estado de investigar, processar, julgar e reparar graves violações de direitos humanos".

A revisão da lei era um dos assuntos mais divisivos da CNV, e não se deu de forma unânime. Foi aprovada por cinco dos seis integrantes - José Carlos Dias, Maria Rita Kehl, Paulo Sérgio Pinheiro, Pedro Dallari e Rosa Cardoso - mas rejeitada pelo advogado José Paulo Cavalcanti Filho. Segundo o relatório, Cavalcanti Filho divergiu pelas "mesmas razões" que fizeram o Supremo Tribunal Federal recusar, em 2010, a revisão da anistia. No julgamento de quatro anos atrás, ao considerar uma Arguição de Descumprimento de Preceito Fundamental proposta pela Ordem dos Advogados do Brasil, o STF considerou, por 7 votos a 2, que não cabia revisão da Lei da Anistia. O voto vencedor, do ministro Eros Grau (aposentado), considerava que a lei não poderia ser modificada pelo Judiciário pois seria fruto de "acordo político" realizado no período final da ditadura.

Apesar da decisão do STF, há significativos fatos históricos a contrapor a tese de "acordo político" vencedora na

corte.

\section{CNBB, 02/10/2013 - Estatuto do Nascituro - em defesa da vida}

Nascituro é o ser humano já em formação, mas ainda não nascido. O Projeto de Lei no 478 , de 2007, que visa proteger o nascituro, tramita há seis anos no Congresso Nacional. Pouco a pouco, porém, vai avançando. Recentemente, ele foi aprovado pela Comissão de Finanças da Câmara, depois de já ter passado também pela Comissão de Seguridade Social e Família. Falta passar pela Comissão de Constituição e Justiça da Câmara e, finalmente, ir ao Plenário da Câmara e do Senado e receber a sanção presidencial, se tudo correr bem.

É um longo e penoso percurso que deve enfrentar uma lei boa. Na prática, além da lei que veta o aborto, no Brasil ainda não há nenhuma lei que garanta mais amplamente um mínimo de respeito e direitos ao ser humano ainda não nascido, mas que já existe e está em gestação no ventre da mãe; é como se a sociedade e o Estado nada

tivessem a ver com as eventuais agressões, discriminações ou outras formas de violência contra os nascituros; nem fossem obrigados a fazer algo para assegurar a sua saúde, antes do nascimento. Seres humanos frágeis e indefesos, na prática, ainda estão entregues à lei da selva!

O Estatuto do Nascituro prevê que ao embrião, ao feto e à criança ainda não nascida seja reconhecida a dignidade humana e, como consequência, que já seja merecedora de proteção jurídica. Isso é um avanço, pois supera uma concepção redutiva das responsabilidades do Estado sobre os seres humanos já concebidos, mas ainda não nascidos: na situação atual, o bebê, antes de nascer, é um "problema" apenas da família ou, até mesmo, só da mãe... Certo discurso em favor da legalização do aborto pretende que unicamente a mulher tenha o direito a decidir sobre o fruto de suas entranhas: deixar viver ou não...

O Estatuto do Nascituro prevê que seja respeitado, antes de tudo, o direito à vida desse ser humano, ainda em formação, mas já existente e vivo; além disso, o direito à saúde e à assistência médica, paga pelo Estado, e às condições para o sadio desenvolvimento, mesmo antes de nascer.

Estabelece ainda que o nascituro tenha direitos patrimoniais, como o de herança, da mesma forma como os filhos já nascidos; tal direito, evidentemente, só se concretiza se ele vier, de fato, a nascer. Também assegura que o nascituro não deve ser maltratado, negligenciado, explorado como se fosse uma "coisa", até para fins econômicos, nem pode ser vítima de crueldade, ou qualquer forma de violência.

Também prevê que haja políticas sociais para que o nascituro encontre condições favoráveis para o seu desenvolvimento integral. Não parece pretensão exagerada para uma sociedade de humanos, com sensibilidade e sentimentos humanos, assegurar às crianças não nascidas esses direitos e essa justa consideração... É difícil compreender que possa alguém ser contrário. O Projeto de Lei pode ser melhorado e poderá sofrer alterações no longo percurso que ainda deve enfrentar. É uma pena que não se aprove logo algo tão salutar! 
Mas o Estatuto do Nascituro, apesar de ser, certamente, bom e de efeitos civilizatórios relevantes, sofre forte oposição, sobretudo porque ele acabaria sendo uma barreira contra a liberação cada vez mais ampla do aborto; por isso, ele enfrenta a forte oposição dos grupos militantes em favor do aborto; geralmente, o argumento é que o direito do nascituro diminuiria o direito da mulher. É bastante estranho e cínico jogar o filho contra a mãe, ou a mãe contra o filho... Ao proteger o nascituro, a lei, de fato, também está valorizando a mulher que gera o filho.

A questão crucial continua sendo a do início da vida humana: quando começa a existir um novo ser humano? A posição da Igreja, que está em concordância com a ciência e a mais elementar constatação da lógica e do bom senso, é esta: a fecundação do óvulo por um espermatozoide e o consequente início da multiplicação das células constituem o início da existência de um novo ser humano. A partir desse momento, passa a existir um novo sujeito de direitos, que precisam ser devidamente assegurados pelo Estado. São direitos próprios à condição do ser humano na fase do seu desenvolvimento pré-natal.

É falacioso argumentar que uma lei favorável aos direitos do nascituro seria prejudicial para os direitos da mulher. Ninguém é obrigado a gerar um filho; mas a partir do momento em que isso acontece, o novo ser humano tem dignidade e direitos a serem respeitados. A dignidade e os direitos da mulher também precisam ser assegurados, de maneira própria e adequada; mas seria chocante se isso fosse feito mediante a negação da proteção à dignidade e aos direitos do filho ainda não nascido.

(Cardeal Odilo Pedro Scherer, Arcebispo de São Paulo e Presidente do Regional Sul 1 da CNBB, Publicado em

O SÃO PAULO, ed. de 18.06.2013)

\section{ADENDO D}

\section{Carta Capital, 07/01/2014 - 'Bolsa Estupro': quando a vítima se torna criminosa}

Para especialistas, Estatuto do Nascituro viola direitos das mulheres e as incentiva a considerar crime o abortamento em casos de estupro

por Marsílea Gombata — publicado 06/06/2013 16h19, última modificação 07/06/2013 09h52 Apoiada pelas bancadas religiosas do Congresso Nacional, a chamada 'Bolsa Estupro' cria o risco de transformar a vítima em criminosa. Segundo especialistas ouvidas por CartaCapital, o texto do Estat uto do Nascituro (aprovado na Comissão de Finanças e Tributação da Câmara dos Deputados na quarta -feira 5)viola direitos das mulheres e as incentiva a considerar crime o aborto em casos de estupro.

"Na medida em que se paga para ela não fazer esse aborto, é como se a vítima passasse a ser a criminosa", avalia Flávia Piovesan, professora doutora de direito na PUC-SP e integrante do Cladem (Comitê da América Latina e Caribe para a Defesa dos Direitos da Mulher). "É um desrespeito a essa mulher estuprada e violentada quando, na minha avaliação, deveríamos assegurar sua autonomia, direito à saúde e dignidade para que decida se quer ou não proceder com uma gravidez indesejada." O texto - originalmente de autoria dos deputados federais Luiz Bassuma (PT-BA) e Miguel Martini (PHS-MG) e que teve parecer favorável do deputado Eduardo Cunha (PMDB-RJ) - prevê acompanhamento psicológico a vítimas de estupro e, na hipótese de a mãe não dispor de condições econômicas suficientes para saúde e educação da criança, garante que "o Estado arcará com os custos respectivos" até que venha a ser identificado o pai ou o bebê seja adotado.

Além de ser criticado por incentivar vítimas de estupro a terem o bebê fruto de violência sexual, o projeto prevê que a mãe estabeleça vínculo com o autor do estupro. $O$ texto determina que, se identificado, o agressor seja obrigado a pagar pensão alimentícia à criança, o que pressupõe contato regular da mulher violentada com o criminoso. "Trata-se de uma violência à nossa dignidade. Além de dar status de paternidade ao estuprador, nos obriga a ter uma relação de proximidade com ele. Ou seja, de alguma forma, legitima a violência sexual e remedeia a vítima 'criminalizada' com uma bolsa", critica Jolúzia Batista, socióloga e assessora do CFEMEA (Centro Feminista de Estudos e Assessoria). $\mathrm{Na}$ sessão da comissão de quarta-feira, o deputado Cláudio Puty (PT-PA) criticou a proposta e alertou para o fato de ela "colocar em primeiro lugar o direito do estuprador, em segundo lugar o direito do feto e, em terceiro lugar, o direito da mulher que foi vítima de uma violência". Sua posição foi vencida na comissão, entretanto.

Saúde pública

Para Jolúzia, além de abrir um "precedente perigoso" para que direitos conquistados - como a decisão favorável do STF ao aborto de anencéfalos - sejam retirados, a proposta toca em um ponto delicado da saúde no País: os abortos clandestinos. "Atualmente, o aborto representa a quinta causa de mortalidade materna no Brasil. Cerca de 4 milhões de mulheres recorrem anualmente ao aborto em condições clandestinas", lembra Jolúzia. "É fundamental que seja, então, visto e amparado como um ato seguro do ponto de vista de saúde pública." 
Em março, o CFM (Conselho Federal de Medicina) defendeu a liberação do aborto até a $12^{\mathrm{a}}$ semana de gestação e enviou à comissão do Senado responsável pela reformulação do Código Penal um documento sugerindo que a interrupção da gravidez até o terceiro mês seja permitida em casos que vão além daqueles envolvendo riscos à mãe, anencefalia de fetos ou estupro. Para o CFM, o aborto deve deixar de ser crime também se houver emprego não consentido de técnica de reprodução assistida, se o feto padecer de graves e incuráveis anomalias que inviabilizem a vida independente ou se for a vontade da gestante até a $12^{\mathrm{a}}$ semana de gravidez.

A Comissão de Bioética e Biodireito da OAB (Ordem dos Advogados do Brasil) do Rio de Janeiro também emitiu um parecer crítico em relação à decisão da comissão, no qual ressalta problemas ao atribuir "personalidade jurídica" ao nascituro, "que é tratado como pessoa, gozando dos direitos assegurados à criança e ao adolescente, atendimento no SUS, dentre outros". Além disso, atentou para a necessidade de não se confundir nascituro e embrião: enquanto "o primeiro diz respeito ao ser humano já no contexto de uma gestação, o segundo se refere ao material biológico proveniente da concepção, do encontro dos gametas masculino e feminino". Parlamentares x STF

O Estatuto do Nascituro não parece ser uma iniciativa isolada. Para Flávia, a proposta faz parte de uma estratégia das bancadas religiosas frustradas com posições do STF (Supremo Tribunal Federal) em reafirmar garantias constitucionais. Seria, portanto, uma resposta a decisões do Supremo como o sinal verde dado à interrupção da gravidez de anencéfalos e às pesquisas com células-tronco de embriões. "Sem contar que é um retrocesso à garantia prevista no nosso Código Penal, de 1940", diz sobre o artigo 128, que permite o aborto em caso de violência sexual. "O estatuto retrocede o mínimo que se conseguiu até agora em caso de estupro e risco de vida. Vejo-o como um movimento perigoso."

O polêmico projeto de lei ainda será analisado pela Comissão de Constituição e Justiça e de Cidadania da Câmara. Se aprovado, vai para votação no plenário.

Recebido em 20/10/2018.

Aceito em 27/02/2019. 